we are able to show it experimentally or not, there is, I suppose, very little doubt of the fact that the materials formed pass somehow or other into blood; and, when we compare these results of supra-renal injection with the converse effects obtained from the removal of supra-renals and from disease of supra-renals, we can come to no other conclusion than that we have before us a well-marked instance of an internal secretion. The general results to which we are led from a consideration of these facts, and others to which I have had no time so much as to allude, point strongly in favour of a theory of internal secretions, and it is obvious that such internal secretions may be of no less importance than the better recognised functions of the external secreting glands. These internal secretions have to be definitely reckoned with by the physician, while at the same time the therapeutist will be able to avail himself of the active principles which they contain, and in certain cases to use extracts of internally secreting glands in place of the hitherto more commonly employed regetable medicaments. That the subject has a vast future there can be no doubt, for, in spite of the adrances which have been made in elucidating it during the last few years, a great number of points still remain obscure. Nevertheless, the way which the physiologist has attempted to show may be followed by the practitioner, and the result of these physiological experiments may now be utilised for the diagnosis and treatment of disease.

\section{ON THE PREVENTION OF PHTHISIS.}

BY JAMES NIVEN, M.B. CANTAB.

MEDICAL OFFICER OF HEALTH TO THE CITY OF MANCHESTER.

IN the issue of Public Health for December, 1894, is a paper read by Dr. Henry Armstrong before the North-Western Branch of Medical Officers of Health on the above subject, in which he does me the honour to quote my name in connexion with preventive measures. He does not, however, agree with the summary of measures which he ascribes to me as being those on which I should rely. This summary reads thus : (1) notification (compulsory) as in fevers ; (2) isolation (with legal procedure for breach of law, as in fevers) \&c. (3) disinfection; and (4) diseased meat (destruction of). Now in the issue for April, 1893, of the same publication I have clearly set out the lines of preventive action on which I should go, and these I will repeat as a basis of comment; but before doing so I should like to say that, no doubt unconsciously, Dr. Armstrong has quite misunderstood my position. I have never proposed isolation with legal procedure for breach of law as in fevers, nor have I thought of such a proceeding. On the contrary, $I$ am under the impression that an isolation hospital would be regarded as a boon by many families one of whose inmates was phthisical, and that there would be no need of compulsion, which I quite agree with Dr. Armstrong in regarding as impracticable. Then, again, I consider the destruction of tuberculous meat as by no means so important as many other precautions, although, of course, not a thing to be neglected. In the paper in question I do not think that I have even mentioned diseased meat. That subject was raised by Dr. Armstrong himself at the same meeting of the Society of Medical Officers of Health at which I gave the paper alluded to, and I there mentioned that the North-Western Branch of the Society had passed a resolution that the carcase of an animal should be condemned if any tuberculosis wis found in it; but of the proposals which I put forward it formed no part. Then, again, disinfection of rooms should be carried out, if possible; but this, again, is not part of the main front of my position. In fact, the proposals put forward to be condemned are, in part, not my proposals at all, and, where they are, they are not in their proper position of importance. Further, at the meeting in question I was present as a representative of the North-Western Branch to make proposals in regard to the infective element in tuberculosis. 'The various adjuvants in the establishment of infection, such as bad housing and bad personal habits, were necessarily, from want of time, put aside for the time being. In the causation of phthisis two factors are concerned-the conveyance of infection and those conditions of the system which favour the lodgment and growth of the tuberculous infection. The second factor plays a much more iusportant róle in the origin of phthisis than it does in many other diseases. It is, however, a rôle much more difficalt to survey and discern than the more immediate part played by the transference of infective material, and it is also a rôle much more difficult to prevent. So far as it is prezentable with special reference to tuberculosis, it wonld be prevented in the course of the measures aclopted to intercept the conveyance of the tuberculous infection. For pumpeses of simplicity of treatment and clearness it is made incidental to the study of the direct transmission of taberculous infection.

The main positions which it is necessary to bear in mind in planning out measures of prevention against the spread of tuberculosis are these:- -1 . Without the importation of the tubercle bacillus or its spores into the system taberculosis cannot arise. 2. Phthisical poople, especially in the later stages of the disease, discharge enormous quantities of tubercle bacilli and spores in their sputum. These are probably innocuous till dried. When dried and dispersed as. dust this sputum is capable of lighting up tuberculosis. Schill and Fischer's investigations showed the prolonged vitality of tuberculous spores in spntum, and Cornet's researches established that the dust taken from a room in which a phthisical person was being treated was liable to convey the disease to guinea-pigs when taken from places which the sputum could not have directly: reached. He found, also, that where the sputum had been carefully destroyed, such dust was not capable of reproducingt the disease in guinea pigs. Moreover, the dust of streets. even where phthisical persons were known to spit, did not produce the disease in guinea-pigs. 3. Cornet's research on the mortality of Catholic nurses in Germany showed thatk intimate exposure to tubuculous dust of healthy individuals was followed by an enormous mortality, the period between exposure to this influence and death being between two and three years. Two years previously, in my report on the health of Oldham for 1891, I had given an account of a number of instances in which people who had died from phthisis had been intimately exposed to infection at a varying period before death, and arrived at the conclusion that the average latent period between exposure to infection and death was probably between two and three years. Again, in the report for 1890 I gave an account (which was reproduced in The Practitioner) of a series of 100 deaths from tuberculosis into which I had instituted an etiological inquiry. In more than half of these cases intimate exposure to infection was ascertained at a period which could be regardeo as the starting point of the infection, and these comprised practically all the cases in which there was not some condition of health strongly predisposing to successful invasion by a comparatively small amount of infectious material. Dr. Heron, in his work on the Communicability of Consumption, gives a very interesting series of cases, collected by Professor Koch, of exposure to infection followed by tuberculosis. Perhaps the most striking of these clinical experiences are those in which exposure of a wound to tuberculous material has been followed by local tuberculosis, subsequently extending to the lungs. 4. Other tuberculous discharges besides sputum contain the infective matter, and are in like manner, though to a less degree, dangerous. 5 . The infective matters from phthisical patients are capable of destruction by chemical agents and are easily destroyed by steam. In the shape of pure cultivations, and therefore as dust, they are readily destroyed by direct sunlight. This is a fact of cardinal importance. 6. Tuberculosis is widely distributed amongst the mammalia and is especially destructive to milch cows. In particular it has been shown experimentally that the milk of tuberculous cows is capable of lighting up the disease in guinea-pigs, especially if the udders are affected by the disease. There is, more. over, good reason on other grounds for beliering that the milk from tuberculons cows is responsible for much of the tuberculous disease of children. So far as tuberculous meat is concerned, the grounds for believing it to be a source of abdominal tuberculosis are mainly experimental. 7. Phthisis is not rare amongst country people, and it is unfortunately only too common amongst milch cows. It was suggested to me by my friend $\mathrm{Dr}$. Robertson of Oldham that the cycle was completed, so far as pulmonary phthisis is concerned, by the cows swallowing the tuberculous matter discharged from the lungs, which subsequently was voided by the cows undestroyed. Anyone acquainted with the condition of cowsheds in this country will at once perceive how very likely it is that phthisis is handed on in 
this manner. The absence of light and ventilation, the frequent presence of tuberculous cows in the sheds, and the dusty condition of many of them, give to this sugrestion a capital importance.

The proposals which I put before the society were based on these and kindred considerations. They were:

1. The memorandum of the North-Western Branch of the Society of Officers of Health or some equivalent form should be placed by sanitary authorities in the hands of all medical men, and as far as possible in the hands of all phthisical patients--" It would be well, also, to issue a brief handbill co every house, at all events in towns, giving simple directions as to the most important precautions. This was done in oldham in 1887, 1888, and 1892." Last year a handbill, of which the following is a copy, was sent to every house in the city of Manchester:-

\section{PRECAUTIONS AGAINST THE COMMUNICATION OF} CONSUMPTION.

1. Consumption is an infectious disease likely to be communicated more particularly in damp, badly ventilated, and badly lighted houses and workshops.

2. It is usually communicated by the matters coughed up by consumptive people, which get dried and dispersed as dust, thus reaching the lungs of those susceptible to the disease.

3. Such matters should, therefore, never be allowed to get dry. For that reason they should not be spat on the floors of a house, but either into pieces of rag or paper, which should be at once burned, or into a hand-vessel containing water. This vessel should be emptied into the drains outside the house once a day, and then ecalded and recharged with water.

4. Everyone affected with a chronic cough should take the same precautions as a consumptive person.

5. The same precautions should be observed in a workshop as at home.

6. Consumptlve people should not spit into a pockethandkerchief, as both the handkerchief and their clothes are thus made infectious.

7. No one should spit on the ground inside any building or in a public converance.

8. The bowel discharges of consumptive people should be disinfected by being passed into a 15 per cent. solution of carbolic acid or simply into water, and the vessel, when emptied, should be at once scalded. sinto water, and the vessel, when emptied, should be at once scalded.
Soiled cloting should be at once removed, disinfected, and afterwards Boiled.

9. When it is settled that anyone is consumptive the house should be thoroughly disinfected, and the patient should be thenceforward conthe to certain parts of the house. On a request made in writing to the Health Office disinfection will be carried out by the department tree of charge.

10. The rooms occupied by a consumptive person should be kept well ventilated and well lighted. This will greatly aid in destroying the infection.

11. No one is more liable to inhale the dust from matters coughed up than the consumptive himself. The removal of infectious matter is, therefore, calculated to promote his recovery. Moreover, if these precautions are strictly carried out he need not be a source of danger to anyone.

12. It is the duty of the attendant to see that the above precautions in regard to the phlegm and discharges are observed, and also to see that every obstacle to sufficient lighting and ventilation is removed.

13. In case of death the house will be disinfected by the sanitary authority, if this is desired. A new tenant should not enter a house previously occupied by a consumptive person until such house has previously occupied by a conghly disinfected.

14. Amongst the agencies which act powerfully in causing con14. Amongst the agencies which act powerfully in causing con-
sumption are damp dwellings and workshops, overcrowding, defective sumption are damp dwellings and workshops, overcrowding, defective and alcoholic excess. These should be avoided.

15. The milk from consumptive cows is very dangerous, especially 15 . The milk from consumptive cows is very dangerous, especially
to children. All milk should be boiled before use. As many animals to children. All milk should be boiled before use. As many anily
suffer from consumption all meat should be thoroughly cooked.

JaMEs NIVEN, Medical Officer of Health.
Public Health Office, Town-hall, Manchester, May 28th, 1894. .

An admirable handbill has also been distributed by Mr. Vacher, medical officer of health to the county of Chester. The memorandum of the North-Western Branch was drafted by Mr. Paget, medical officer of health for Salford, in 1892, following on papers given by Dr. Ransome and myself to the branch in that year. It is admirably drawn and very well adapted for its object, which was rather to convey full information to phthisical families, and to serve as a basis for the medical attendant to give instructions upon, but is, I think, too detailed for a handbill to be generally distributed. To this general education of the public I attach the very utmost importance. If the public anind is not diligently and adequately prepared by the diffusion of information on the subject it is too much to expect that public bodies will be roused to take the necessary action, or that the general public will support them, or the officers whose duty it may be to carry out their instructions. Moreover, without any further proceeding whatever an immense impetus is thus given to the carrying out of precautionary measures. I have been assured that in Oldham it had become a very common practice to carry out preventive measures.

8. Tuberculosis should be made a notifiable disease-- notifiable under the same Acts and umler similar conditions to such diseases as scarlet fover. 'The inclusion of tuberculosis amongst notifiable diseases conld be effected under Clause 7 of the Infectious Discases Notification Act, 1889. What, then, are the reasons for proposing such a step)? In the first place, whatever the concomitant conclitions, tuberculosis is an infections discase, the moles of propagation of which we know with great definiteness. It is especially in the later stages of the discase that the largest amounts of infectious material are being discharged from the system, and notification would, therefore, be valuable at any period of the disease. It is, moreover, especially in the later stages when phthisical patients require nursing and constant attention, and when through weakness their personal habits are liable to become most negligent that those in contact with them are exposed to the greatest amount of risk. I would propose at first to exclude from notification cases of closed glandular, bone, and joint affections, and only to deal with such cases as from the presence of discharges, whether from the lungs, mouth, skin, or bowels, are manifestly liable to convey the disease. I do not agree with Dr. Armstrong that the expense of such notification would be enormous, and I have given figures ${ }^{1}$ to show that such would not be the case. If these data are regarded as unreliable, or if more satisfactory figures can be produced, it would be well to have them. One objection to notification it would be necessary to deal with--viz, the difficulty entailed by phthisical patients changing their medical attendant, as they frequently do. It is, in my opinion, indispensable, whether notification is to be-at first-compulsory or voluntary, that the usual fee of $2 s$. $6 d$. a case should be paid. To prevent, therefore, undue expense each patient reported would be furnished with a card bearing the date of notification of his case, which he would be required to produce on application for disinfectants, \&c. Medical men would be requested to ascertain whether their patients had been previously notified, and not to notify a case a second time except on change of acldress. Even if such a precaution was not carried out I do not see that the expense would be such as to be a bar to notification. What are the objects to be gained by notification? In the first place the precautionary measures to be taken by the phthisical individual or his attendant would be prescribed and carried out. In the second place the conditions of the house favouring the spread of the disease would be ascertained and as far as possible removed. The conditions of work of other inmates of the household favouring the disease would be ascertained and as far as possible guarded against. Disinfection of the rooms occupied by the patient would be effected. The dangers of exposure of members of the family suffering from any condition of lowered vitality would be pointed out.

The circumstances attending the commencement of the disease would be investigated, and doubtless in this way considerable light would be thrown on its food relations. But, above all, the insanitary conditions which have been shown to bear such an intimate relation to phthisis, and which play a far more important part in the production of that malady than in any other infectious disease, would be investigated and removed precisely at the time when they were most dangerous both to the patient and to the other members of the family. On Oct. 24th and Nov. 7th, 1893, the subject was discussed by the Medical Society of Oldham. It was found that considerable hesitation existed with reference to the notification of tuberculosis, and that more particularly apprehensions were entertained that the sanitary officials would interfere between the medical attendant and his patients. No objections, however, were offered to a paper of instructions as to personal precautions being handed in by the sanitary inspector on which the medical attendant could enlarge. After full debate the members of the society agreed in recommending the voluntary notification of phthisis. It may be as well to recall the general position arrived at on that occasion, since it is, so far as I know, the only expression of opinion formulated by a body of general practitioners. 'The following notice of the meeting was given in THE LANCET of Nor. 18th, 1893:-

"OLDHaM MredCaI SocLeTr.-On Oct. 24th a discussion on the subject of Notification of Phthisis was opened by Mr. Fawsitt, President of the Society, at a very full meeting. Several members took part in the discussion, and at the close of the meeting the subject was adjourned to having expressed their views on the question, it was understood that 
the objects of notification would be: 1 . The sanitary authority would disinfect the room occupied by the tuberculous patient, as might be required. 2. Inasmuch as the transmission of tuberculosis is in a large proportion of cases determined by the presence of insanitary conditions, such as damp, overcrowding, deficiency of light, and so forth, an opportunity would be afforded to the authority of removing such conditions and so saving other members of the household. 3. Further evidence would be collected bearing on the modes and conditions of transmission of the disease. 4. The personal hygiene of the patient would in no way come under the care of the sanitary authority; it was hoped, however, that the medical attendant would confer with the medical officer of health, when convenient, as to the precise means by which tuberculous discharges might be most usefully destroyed. At the same time the sanitary department would in no way interfere with the treatment of the patient, and all instructions in dealing with discharges from the patient would come from the medical attendant. 5 . Only such cases would be reported as were taking place from the lungs, cases with tuberculous diarrhoea, and cases with copious discharge from tuberculous bones and tuberculous ulcers. These and other matters having been fully discussed, the following resolution was carried unanimously: "That the society, having had its attention drawn to the infection of tuberculous diseases and to the great mortality and injury to the population arising therefrom, is of opinion that these diseases should be the subject of voluntary notification to the sanitary autbority.' It was understood that a copy of the resolution would be sent to the sanitary committee of Oldham as well as to the medical journals."

Providing the fee of $2 s .6 a$. can be paid for each case reported, I do not object to voluntary notification being first tried, as it will give time practically to ascertain and deal with the difficulties of administration. At the same time it seems to me quite clear that, the connexion between insanitary conditions and the communication of phthisis being so close as it is, this alone would be a sufficient argument for compulsory notification, putting aside the other powerful reasons for it. Nor do I doubt that voluntary notification would speedily result in compulsory notification.

3. My third proposition was that Isolation Hospitals should be provided by sanitary authorities, jointly or separately, at the expense of the rates, for the isolation of cases of tuberculosis likely to cause infection. As it is, workhouse hospitals do at present provide a considerable amount of isolation for the very poor. But there are a vast number of artizan families which would decline to avail themselves of that refuge, and where the patient is a clanger and a burden. I feel quite sure from the conversations I have had in the course of my inquiries that the provision of good hospital isolation would be hailed as a blessing by these poor struggling people, and it would be the means of removing infection from the home. Not only so, but those treated in the hospital for a time would be thoroughly indoctrinated with the measures of precaution taken, which would become part of their daily habit. They would therefore, on their return, be centres for the diffusion of knowledge on the subject. It is in the later stages of the lisease that infection is most likely to occur and that the disease is most burdensome. This is precisely the stage which is not dealt with in convalescent homes, and which should be dealt with in the interests of public health. This proposal is, however, not necessary to the success of the first two.

4. Tuberculosis in cattle should be brought under the Contagious Diseases (Animals) Acts, and special veterinary inspectors should be appointed by sanitary authorities, singly or jointly, to carry out the objects of the Acts in relation to tuberculosis and other diseases, and to attend to the general sanitary arrangements of the cowsheds. I may be allowed to quote the continuation: "The officer to be appointed should be a young veterinary surgeon, well versed in the diagnosis of disease. He should receive a sufficient salary and travelling expenses. His duties should be something like the following. Once a month he should inspect the farm-buildings and note any conditions found on these or on the farms likely to act injuriously on the health of the cattle or on the quality of the milk $\mathrm{He}$ should examine the cattle and ascertain whether they were suffering from any disease. If he saw reason to suspect tuberculosis he should take measures to have the suspected animal isolated, and see that necessary measures of disinfection were carried out. The sale of milk from this animal would be stopped. If his diagnosis was clear and unhesitating the cow should be killed. Compensation should be given, the amount paid to have regard to the condition of the animal. In advanced tuberculosis it would be trifling-in an early stage of the disease such as would not entail any loss to the farmer. It would thus be to the farmer's interest to have such cases reported as soon as possible. Notification would be compulsory on the farmer. Constant practice in diagnosis would soon enable a good veterinary surgeon to have an almost instinctive knowledge of what he was dealing with, unless in very obscure cases. It is so in human diseases. The veterinary surgeon would also deal with the sanitary requirements of the cowsheds. Ordinary insanitary conditions about farms would be attended to by the inspector. I throw out these details merely by way of showing that the veterinary inspector would have enough to do. Having made his investigations, the veterinary inspector would report to the medical officer of health of the district, so that he might be able to coöperate with the veterinary inspector in getting the necessary preventive measures carried ont."

I have already mentioned how in all prokability tuber. culosis is directly communicated in cowsheds from tuberculous cows. But, apart altogether from tukerculosis, the condition of our cowsheds and their relation to the public health through the milk supply demand investigation and rearrangement. It would be of great advantage if the regulations applicable to cowsheds were made uniform, so that any local action taken to improve their condition should not have the effect of transferring the milk-supply to another district perhaps as badly off in the matter of cowsheds as that in which the action was taken.

Oldham.

\section{PERFORATION OF UTERUS BY SOUND OR CURETTE.}

BY LAWSON TAIT, F.R.C.S.ENG.,

CONSULTING SURGEON TO THE HOSPITALS FOR WOMEN AT BIRMINGHAF, NOTTINGHAM, AND SOUTHAMPTON.

THE article by my friend, Dr. Auvard, in the Archives de Tocologie et de Gynécologie, noted in THE LANCET of Sept. 22nd, 1894, has been lying for months on ury desk waiting the leisure the holiday season has given me that I might draw further attention to an interesting occurrence, long ago familiar, but apparently forgotter. When Simpson made the uterine sound practicable, he put it in the hands of every one, and its routine use did a great deal of mischief. Now it is relegated to its proper position, and used only in a very limited area of special practice. We do not, therefore, see now the cases of perforation of the uterus by the sound which were so familiat to Simpson's pupils and followers. In the columns of THE LANCET ${ }^{1}$ I recorded my own first experience of it. stating at the same time the fact that it was well known to Simpson, whom I had often seen demonstrate it. Next month ${ }^{2}$ Mr. Walter Whitehead recorded a case as having happened to Foltz and Petrequin, and narrated by the former before the Lyons Medical Society, where a female catheter, used for the purpose of inducing premature labour. passed through the fundus and was extracted through the umbilicus eighteen weeks after without any bad symptoms. Mr. Whitehead also mentions a fatal case in the experience of a friend. It would be a valuable contribution to the literature of the subject to have an account of this ease, as it is the only disaster of the kind I have ever heard of amongst a number of perforations which I have seen and heard of, 30 great that I should be afraid even to attempt to guess at the total. It must be strictly borne in mind that all the cases of which I speak occurred in the non-pregnant aterus.

Dupuy collected seventeen cases, ${ }^{3}$ in none of which did any subsequent evil effects arise. Commenting on this paper Dr. W. S. Playfair said that it was probable that in many of these cases the sound passed through the Fallopian tubes. This point used to be one of periodic discussion between the late Dr. Matthews Duncan and myself, and I can accept the view shared by him and Dr. Playfair still less now than in the time of those discussions. It is fashionable now to talk of passing sounds and cathetes: through the Fallopian tubes (and ureters). I have tried on the cadaver, but (though fairly nimble with my fingers) have never succeeded, and I have never seen anyone else succeed, though I am far from saying that such passage is an impossibility. Again, I have seen as many pathological
1 THE LANCET, April 29th, 1871.

2 The LANCET, May 13th, 1871 . 3 Progrès Médical, $187 \mathfrak{l}$. 